Department of Social Systems and Management

Discussion Paper Series

No.1297

Dynamical Analysis of the R\&D-based Growth Model

with a Regime Switch

by

Shiro KUWAHARA

July 2012

Tsukuba, Ibaraki 305-8573 JAPAN 


\title{
Dynamical Analysis of the R\&D-based Growth Model with a Regime Switch
}

\author{
Shiro Kuwahara*
}

July 13, 2012

\begin{abstract}
Several empirical studies suggest that advanced economies experience a growth regime switch from factor accumulation to knowledge accumulation. To investigate the mechanism of such a regime switch, this study develops a concise and flexible dynamic model based on Romer (1990) by introducing two types of endogenously supplied R\&D input capital. The model replicates the growth patterns of developed and underdeveloped nations, clarifies the important role that capital plays in the difference between them, and presents several implications for interest-rate subsidies and official development assistance. Further, it shows that if a country enjoying long-run growth has little initial capital, its initial economic development will be based on capital accumulation. When the capital stock becomes sufficient for supporting R\&D, the economy will achieve long-run growth through R\&D.
\end{abstract}

Keywords: dynamics of regime switch, capital-accumulation-based growth, R\&D-based growth, effectiveness of economic policies

JEL Classification: E00, O00, O41

*Address: Division of Policy and Planning Sciences, University of Tsukuba, 1-1-1 Tennodai Tsukuba, Ibaraki 305-8573, Japan. E-mail: kuwahara@sk.tsukuba.ac.jp. Phone/Fax: $+81-29-853-6206$ 


\section{Introduction}

This study focuses on the mechanism of regime switch that underlies economic development. Since Solow (1957), total factor productivity (TFP) growth and growth in human capital through R\&D activities have been considered as a central factor in the determination of long-run growth. However, some studies imply that physical capital too plays an important role in economic growth: Howitt and Aghion (1998) emphasize complementarity between capital accumulation and long-run growth, and present some (indirect) evidence of this property. Howitt and Aghion (1998) construct a model with this complementarity, and Chandler (1990) demonstrates that the scale expansion of enterprises generates $\mathrm{R} \& \mathrm{D}$ and product diversification. Furthermore, some empirical works show that the level of capital accumulation affects the capability and/or profitability of R\&D activities. Abramovitz and David (1973) show that America's economic growth in the early nineteenth century was more dependent on capital accumulation than on TFP growth. Hayami and Ogasawara (1999) report similar results from Japanese pre-war data. These works reveal that economies in the early stages of development grow as a result of capital accumulation, but they subsequently pursue a growth regime that is driven by $\mathrm{R} \& \mathrm{D}$. On these perspectives, some empirical works report that newly industrializing countries in Asia grow mainly through capital accumulation (as reported by Krugman (1994) and Young (1995)), but as Matsuyama (1999) discusses, these results are not itself negative for long-run growth. The important question is whether economies can make a regime switch.

Thus, the main purpose of the present study is to analyze the dynamical properties of economic development with a regime switch, and as such, we construct a model that directly relates $R \& D$ activities and capital accumulation by assuming that both human capital and physical capital are accumulated and invested into R\&D activities. We then replicate the dynamics of a regime switch: namely, we change the growth regime from capitalaccumulation-based growth to R\&D-based growth.

In this regard, we extend Romer's (1990) model that contains endogenouslydriven R\&D activities, yields steady-growth and no-growth steady states, and gives a framework on optimal economic policies. ${ }^{1}$

\footnotetext{
${ }^{1}$ Dynamical analysis and proof of stability were given by Arnold (2000).
} 
Regime change and the realization of long-run growth have attracted attention in this decade because of their connection with the endogenous growth theory. Some theoretical works produce models for describing the regime change from capital-based growth with decreasing returns to long-run positive growth (Zilibotti 1995; Matsuyama 1999; Funke and Strulik 2000; Galor and Moav 2004; Irmen 2005; Kuwahara 2007). The present study shares its purpose and structure with those of Zilibotti (1995), Matsuyama (1999, 2001), Irmen (2005) and Kuwahara (2007), who focus on the regime switch from capital-based growth to R\&D-based growth. While Zilibotti (1995) and Irmen (2005) conduct an analysis by using the model of a competitive economy, Matsuyama (1999, 2001), Kuwahara (2007), and the present study use models with monopoly power, which stems from the intellectual proprietary right created by $R \& D$ activities. While Matsuyama (1999) and Kuwahara (2007) assume instantaneous monopoly power in the R\&D sector and focus on the multiplicities of the economic path, ${ }^{2}$ the present study focuses on long-run growth with the regime change as a one-off, epoch-making event in economic development. In our study, the obtained growth path is a unique saddle-stable one, and no multiple equilibrium is obtained. However, this uniqueness makes it possible to definitely analyze economic welfare.

Our main modification to Romer's (1990) model is the consideration that both human capital and physical capital are used in R\&D. This transformation of assumptions yields a regime switch in economic growth. The models of Romer (1990) and this paper encompass two growth phases - growth without R\&D (capital accumulation phase) and growth based on R\&D - and have the property that a sufficient stock of R\&D input is necessary for growth based on R\&D. Romer (1990) assumes that R\&D is executed by an exogenously given human capital endowment, ${ }^{3}$ whereas we assume that endogenously supplied capital is used for R\&D activities; hence, the determination of whether or

\footnotetext{
${ }^{2}$ Matsuyama (1999) focuses on the fluctuations between the two economic regimescapital-based and R\&D-based growth - and Kuwahara (2007) concentrates on the multiple steady states derived by expectations.

${ }^{3}$ As early R\&D-based growth models, see Romer (1990), Grossman and Helpman (1991), and Aghion and Howitt (1992), who assume that exogenously endowed human resources and exogenously given $R \& D$ resources uniquely determine the long-run growth (or no growth). Furthermore, in these frameworks, if the R\&D input factor grows, it yields a drastic rise in the economic growth rate, as Jones (1995a, 1995b) critiques. In addition, some studies along this line conclude that introducing capital would not alter the essential outcome (Grossman and Helpman 1991 Ch. 5; Aghion and Howitt 1998 Ch. 3).
} 
R\&D exists is endogenized. Because economic growth accumulates capital, an economy with sufficient capital can shift from growth through only capital stock to R\&D-based growth. This is the brief sketch of the mechanism of the regime switch in our study.

Next, because we obtain a saddle stable path, we can derive optimal policy rules in our model. As Jones (2002, p118) points out, resource allocation for R\&D is distorted by three channels: (i) the "knowledge spillover" effect that is caused by missing the market on $R \& D$ input for future contribution on improving productivity, (ii) the "stepping on toes" effect that is classical externality, and (iii) the "consumer surplus" effect that stems from monopoly pricing. Because our model shares properties, such as a distortion of intermediate goods pricing and freely used public knowledge capital, with the Romer model, it causes a deviation in optimal resource allocation and thus the equilibrium capital stock to be excessively small, and because of a positive relationship between the GDP growth rate and capital stock, a lower GDP growth rate is engendered by a smaller capital stock. This under-accumulation of capital can be eliminated by (only) interest subsidies. Whereas Romer (1990)'s policy analysis provides the result that the determination of the long-run growth regime depends on the endowment of R\&D input, we go one step ahead by endogenizing R\&D input factor accumulation, and as a result, obtain the result that the determination of the long-run growth regime is a deep parameter, such as R\&D efficiency, rather than an endowment. Therefore, our study concludes that any policy - that adds factor endowment - has no effects on the long-run growth phase. Thus, this optimal policy can enhance economic welfare, and affect the economic growth rate. However, this optimal path for an economy with low efficiency leads to a steady state with no growth path. In such a case, it is impossible to set the economy on a long-run growth path through an optimal subsidy policy. Namely, it is impossible to set such an economy toward long-run positive growth through extending knowledge, human or physical capital stock. Thus, our study concludes that the effectiveness of official development assistance (ODA) is restrictive and conditional, which is also confirmed by some previous empirical studies; for example, Boone (1996) asserts that foreign aid does not increase growth rates in poor countries, and Burnside and Dollar (2000) report that the effectiveness of an aid policy is conditional.

The rest of the paper is organized as follows. Section 2 establishes the model of a decentralized economy. The existence of the two types of steady 
states and their determinants is explained in Section 3. The dynamic property of the model is analyzed in Section 4, and Section 5 presents a welfare analysis. Finally, Section 6 concludes the paper.

\section{The Model}

There is a competitively supplied final good which can either be consumed as a consumption good (aggregate consumption is denoted by $C$ ) or invested for physical or human capital accumulation (aggregate physical and human capital stocks are denoted as $K$ and $H$, respectively). Denoting final goods production by $Y$, we have the resource constraint on final goods as $Y=$ $\dot{K}+\dot{H}+C$. Physical capital is used as an intermediate good for supplying to the final goods sector $\left(K_{Y}\right)$ and for investment to create new intermediate goods; that is, R\&D $\left(K_{A}\right)$. The market-clearing condition for capital imposes $K=K_{Y}+K_{A}$, where $K$ is the amount of physical capital in the economy. $\mathrm{R} \& \mathrm{D}$ is also assumed to be necessary for the input of human capital $(H)$. Both physical capital and human capital are accumulated by investing in final goods. The economy is populated by infinitely lived representative agents; its population is given by $N$ and its growth rate is assumed to be exogenously given at a constant $n$. One unit of population is assumed to inelastically supply one unit of labor; thus, aggregate labor supply can be identified with the economy's population scale. We assume that the economy is closed, final goods are numéraire, and time is continuous.

The present study adopts a Romer-type production structure adopted in Arnold (2000) - there are three primary factors of production: capital $(K)$, labor $(N)$, and knowledge $(A)$. Labor goes directly into the production of final goods, and the capital used in production is first converted into a variety of differentiated and patented intermediate goods, which are indexed by $i$. The number of intermediate goods is denoted by $A$. These intermediate goods are aggregated by a symmetric CES, which in turn is combined with labor by means of a Cobb-Douglas technology. Thus, $A$ denotes the scale of the cluster of the variety of intermediate goods, which gives the technological level in the economy, and $A$ can consequently be regarded as the level of knowledge accumulation, or knowledge capital. Then, the production 
function is specified as

$$
Y=N^{1-\alpha} \int_{0}^{A} x(i)^{\alpha} d i, \quad 0<\alpha<1,
$$

where $x(i)$ denotes the amount of intermediate good $i$, and $[0, A]$ represents the range of intermediate goods available in the current marketplace.

One unit of an intermediate good is assumed to be produced by $\eta$ units of capital. Therefore, the capital allocated to the production of final goods $K_{Y}$ is quantified as $K_{Y} \equiv \int_{0}^{A} \eta x(i) d i$. In a symmetric configuration regarding intermediate goods, the equation $x=x(i)$ converts the definition equation of $K_{Y}$ into $K_{Y}=\eta A x$, or equivalently, $x=(1 / \eta)\left(K_{Y} / A\right)$. Since we assume that final goods $Y$ are consumed as consumption goods or invested in physical or human capital accumulation, the following resource constraint for final goods holds:

$$
(Y=) \eta^{-\alpha} N^{1-\alpha} H_{Y}^{\beta} A^{1-\alpha} K_{Y}^{\alpha}=\dot{K}+\dot{H}+C,
$$

where $\dot{Z}$ denotes an increment in the value of $Z$.

The final goods sector is competitive, and Eq. (1) yields the first-order conditions (FOCs) of the production of final goods. These are given as $\frac{\partial Y}{\partial N}=$ $w$ and $\frac{\partial Y}{\partial x(i)}=p(i)$, where $w$ and $p(i)$ denote the real wage and the price of the $i$ th sector intermediate goods, respectively. In this setting, the rental price of human capital $r_{H}$ is equalized to be that of physical capital $r$ if the human capital investment is executed.

In our model, all intermediate goods are protected by non-perishing patents and the $i$ th firm innovates the idea of $i$ th intermediate good, holds the patent for the $i$ th intermediate good, and is a monopolistic supplier of the $i$ th intermediate good. From the necessary condition that $\eta$ units of capital are required to produce one unit of intermediate goods, the profit of the firm producing the $i$ th intermediate good is given as $\Pi(i) \equiv p(i) x(i)-r_{K} \eta x(i)$, where $r_{K}$ is the rental price of capital, and the firm producing the intermediate good maximizes this profit subject to the demand restriction $\frac{\partial Y}{\partial x(i)}=p(i)$. Under the symmetric configuration, this optimization condition yields the following: $x(i)=\bar{x}=\left(\frac{\alpha^{2}}{r_{K} \eta}\right)^{\frac{1}{1-\alpha}} N$, and $p(i)=p=\frac{\eta r_{K}}{\alpha}$. From Eq. (2) and the FOCs, wage rate $w$ and interest rate $r$, and the profit from the production of intermediate good $\bar{\Pi}$ are, respectively, obtained as $w=(1-\alpha) \frac{Y}{N}, r_{K}=\alpha^{2} \frac{Y}{K_{Y}}$, and $\bar{\Pi}=\Pi(i)=\alpha(1-\alpha) \frac{Y}{A}$, where, in equilibrium, the profit of each firm producing an intermediate good is equalized. 
Therefore, $\bar{\Pi}=\Pi(i)$.

R\&D firms create new intermediate goods, and their patents stream perpetual monopoly profits $\bar{\Pi}$, which comprise the revenue of R\&D. Thus, the present value of this stream represents the value of $\mathrm{R} \& \mathrm{D}: \bar{V}(t) \equiv \int_{t}^{\infty} \bar{\Pi}(\tau) e^{-\int_{t}^{\tau} r(s) d s} d \tau$. Free entry of $R \& D$ is assumed. Therefore, if revenue from $R \& D$ exceeds its costs, an infinite amount of capital would be allocated to $R \& D$. Thus, revenue from $R \& D$ cannot exceed the cost in equilibrium. If revenue from $R \& D$ does not exceed its cost, investment in R\&D is unprofitable, and no resources are allocated to R\&D. In this case, an equilibrium without $\mathrm{R} \& \mathrm{D}\left(K_{A}=H=0\right)$ occurs. Thus, if the economy is in equilibrium with positive $R \& D$ investment, the revenues generated by $R \& D$ must be equated to its cost.

Since we assume that both human capital and physical capital are invested to undertake $\mathrm{R} \& \mathrm{D}$, firms that engage in $\mathrm{R} \& \mathrm{D}$ must pay a rental cost $r$ for their R\&D activities in the process of innovation. Furthermore, innovation is assumed to be the discovery of new intermediate goods that are added to the existing set of intermediate goods; therefore, the expansion of the variety of intermediate goods can be shown by the time derivation of knowledge capital, $\dot{A}$.

Finally, we assume that each R\&D firm has one innovation; conversely, each innovation has one patent. Therefore, the value of such a firm comprises the "value" of one innovation. Then, the aggregate value in the macroeconomy is the summation of the values of all these firms, $\bar{V} A$; the aggregate innovated value by R\&D and its input cost are given as $\bar{V} \dot{A}$ and $r K_{A}+r H$, respectively. Thus, the profit from R\&D firm is given as $\bar{\Pi}^{R}=\dot{A} \bar{V}-r\left(K_{A}+H\right)$ and the free entry condition on $R \& D$ activities yields the following relationships between market equilibrium and capital allocation:

$$
\left.\begin{array}{l}
\text { Solow Regime: } K_{A}=H=0 \\
\text { Romer Regime: } K_{A}, H>0
\end{array}\right\} \Longleftrightarrow r\left(K_{A}+H\right)\left\{\begin{array}{l}
> \\
=
\end{array}\right\} \bar{V} \dot{A} .
$$

Whether an economy conducts R\&D depends on condition (3). When $K_{A}>$ 0 , R\&D occurs, causing the economy to grow through endogenous technological change. Following Matsuyama (1999), we term this regime as the Romer regime. Condition (3) states that the equality $r K_{A}=\tilde{V} \dot{A}$ holds in the Romer regime. When $K_{A}=0$, no R\&D occurs, and the economy grows only by capital accumulation. Following Matsuyama (1999), we term this regime as the Solow regime. In the Solow regime, the system yields the inequality $r\left(K_{A}+H_{A}\right)>\tilde{V} \dot{A}$ for $K_{A}, H>0$. 
On the Romer regime, differentiating $\tilde{V}$ with respect to time provides the following asset equation:

$$
r \bar{V}=\bar{\Pi}+\dot{\bar{V}}
$$

Here, we introduce an R\&D function - a function of increment of new variety $(\dot{A})$ for the R\&D input of physical and human capital $\left(K_{A}\right.$ and $\left.H\right)$-where we assume an R\&D input and that the function deceases with $\Omega(t)$, which captures the increment in $R \& D$ difficulty. More specifically, we assume the following R\&D technology:

$$
\dot{A}(t)=\delta \frac{A(t) K_{A}(t)^{1-\gamma} H_{A}(t)^{\gamma}}{\Omega(t)}, \quad 0<\gamma<1, \quad \delta>0,
$$

where $\gamma$ and $\delta$ denote the input efficiency share between physical and human capital and the total R\&D efficiency parameter, respectively. Following Romer (1990)'s setup, the R\&D function linearly depends on existing knowledge capital $A(t)$, and value of $\mathrm{R} \& \mathrm{D}$ is attributed to $\mathrm{R} \& \mathrm{D}$ input, (human capital in the Romer model) with no R\&D firm residual. Consequently, in the present model, where physical capital and human capital are R\&D inputs, we assume that the R\&D function is homogeneous of degree one in human capital and physical capital, which gives that value of $R \& D$ is attributed to both human capital and physical capital with no R\&D firm residual. Furthermore, $\Omega$ is introduced as in Segerstrom (1998). We need to impose the properties of $\Omega$ as follows: (i) although we need not specify the entire path of $\Omega$, but the growth rate of $\Omega$ in the steady state must be determined (which is done in the next section); (ii) rational agents in this economy are assumed to know the entire path of $\Omega$.

Combining Eqs. (4) and (5), the R\&D firm's profit $\bar{\Pi}^{R}$ yields the FOCs of the R\&D firm as follows: $\frac{\partial \bar{\Pi}}{\partial K_{A}}=0$ and $\frac{\partial \bar{\Pi}}{\partial H}=0$. These conditions give the following relationship on optimal R\&D inputs: $H=\frac{\gamma}{1-\gamma} K_{A}$. Therefore, we have the capital composition ratio on $\mathrm{R} \& \mathrm{D}$ as follows: $\xi \equiv \frac{H}{K_{A}}=\frac{\gamma}{1-\gamma}$. This is given as the rate of human capital against the physical capital devoted to $\mathrm{R} \& \mathrm{D}$, which is given by a deep parameter $\gamma$ and therefore is a constant. Using this relationship, the dynamics of $A$ are given as

$$
\dot{A}=\delta A \frac{K_{A} \xi^{\gamma}}{\Omega}=\delta A\left(\tilde{k}-\tilde{k}_{Y}\right) \xi^{\gamma}, \quad \text { or } \quad g_{A}=\delta\left(\tilde{k}-\tilde{k}_{Y}\right) \xi^{\gamma},
$$

where $\tilde{k}, \tilde{k}_{Y}$, and $g_{A}$ denote the R\&D-efficiency-cost-unit-adjusted (henceforth, R\&D-difficulty-adjusted) values of $K$ and $K_{Y}$ and the growth rate of 
$A$, respectively. More generally, $\tilde{z}$ denotes the $\mathrm{R} \& \mathrm{D}$-difficulty unit value of an aggregate variable $Z$; that is, $z \equiv Z / \Omega$ ). We define the growth rate of variable $Z$ as $g_{Z}$; that is, $g_{Z} \equiv \dot{Z} / Z$.

Under the regime with positive R\&D, using Eqs. (3) and (6) gives the value of $R \& D$ as follows:

$$
\delta \frac{V}{\Omega} \xi^{\gamma}=r(1+\xi), \quad \text { and therefore } \quad \delta \tilde{v} \Gamma(\gamma)=r,
$$

where $V\left(\equiv \bar{V} A=\int_{0}^{A} \Pi(i) d i\right)$ denotes the aggregate value of the R\&D firm, and $\tilde{v} \equiv V / \Omega$ and $\Gamma(\gamma) \equiv \frac{\xi^{\gamma}}{1+\xi}=\gamma^{\gamma}(1-\gamma)^{1-\gamma}$. Because $\delta$ and $\gamma$ are constant parameters and $r$ is a constant in the steady state, (7) implies that $V$ grows at the same rate as $\Omega$ in the steady state. Because we can write $V=\frac{\Pi}{r-g_{V}}$, where $\Pi \equiv \bar{\Pi} A$ and where $\Pi=\alpha(1-\alpha) Y$ is derived from $\bar{\Pi}=(1-\alpha) \alpha \frac{Y}{A}$, it is found that $V$ grows at the same rate as $Y$ at least in the steady state. We specify this in the next section where steady state growth rates are derived.

To conclude the model, we examine the consumption decision of households. It is assumed that a representative household maximizes the utility defined by

$$
U=\int^{\infty} \frac{c(t)^{1-\theta}-1}{1-\theta} e^{-\rho t} d t, \quad \theta>0,
$$

subject to a budget constraint, where variable $c$ denotes per capita value of consumption $C$, and deep parameters $\rho$ and $\theta$ denote the subjective discount rate and constant relative risk aversion (CRRA), respectively. Furthermore, we assume that this household also has a rational expectation. Namely, since the economic path in this study includes a regime switch, the household accurately expects the period of regime switch and the entire sequence of factor price on the super-long-run economic development process. Under these assumptions, we have an ordinary optimal condition regarding consumption called the Keynes-Ramsey rule:

$$
\theta \frac{\dot{c}(t)}{c(t)}=r(t)-\rho-n
$$

\section{Two Types of Steady States}

We now analyze an economy in a steady state, wherein all variables grow at constant rates. As shown below, our model contains two types of steady states: one with R\&D (and therefore, positive growth) and the other without 
R\&D (and therefore, no growth). We call these types of states the Romer steady state (RSS) and the Solow steady state (SSS), respectively.

From the discussion in Section 2, we obtain the following. The first and second terms in (2) give the growth rate of $Y$ as $g_{Y}(t)=(1-\alpha) g_{A}(t)+$ $(1-\alpha) n+\alpha g_{K_{Y}}(t) . H_{A}=\frac{\gamma}{1-\gamma} K_{A}$ implies that the growth rates of physical capital and human capital are the same (namely, $g_{K_{Y}}^{s}=g_{K_{A}}^{s}=g_{K}^{s}=g_{H}^{s}$ ), where $s$ denotes the index on the value in the steady state. The second and third terms in (2) imply that $g_{Y}^{s}=g_{K}^{s}=g_{K_{Y}}^{s}=g_{H}^{s}=g_{H_{Y}}^{s}=g_{C}^{s}$ must hold in a steady state. The discussion in the previous section implies that $g_{\Omega}^{*}=g_{Y}^{*}$ is necessary for the existence of the steady state. Uniting these properties, we have that $g_{Y}^{s}=g_{K}^{s}=g_{C}^{s}=g_{A}^{s}+n=g_{\Omega}^{s}$, or that $g_{y}^{s}=g_{k}^{s}=g_{c}^{s}=g_{A}^{s}\left(\equiv g^{s}\right)$. For convenience, we assume that $\Omega(t)=A(t) N(t)$.

Substituting $g_{c}^{s}=g_{A}^{s}$ into the Keynes-Ramsey rule given in Eqs. (9) and (6), we have

$$
r^{s}=\theta \delta\left(\tilde{k}^{s}-\tilde{k}_{Y}^{s}\right) \xi^{\gamma}+\rho+n .
$$

Applying the notation of R\&D-difficulty-adjusted value to $Y, r, \tilde{\Pi}$, and dynamics of $\bar{V}$, we obtain the following: $\tilde{y}(t)=\eta^{-\alpha} \tilde{k}_{Y}(t)^{\alpha+\beta}, r(t)=\alpha^{2} \eta^{-\alpha} \tilde{k}_{Y}(t)^{\alpha-1}$, $\tilde{\pi}(t)=(1-\alpha) \alpha \eta^{-\alpha} \tilde{k}_{Y}(t)^{\alpha}$, and $\{r(t)-n\} \tilde{v}(t)=\tilde{\pi}(t)+\dot{\tilde{v}}(t)$. These notations imply that $\tilde{y}$ and $r$ can be considered as functions of $\tilde{k}_{Y}$, and that taking Eq. (7) into account, the dynamics of $\tilde{v}$ can be represented by the dynamics of $\tilde{k}_{Y}$.

Thus, in the steady state, the determination of the type of steady state can be summarized as follows:

$$
\begin{array}{r}
\text { Romer Steady States (RSS): } \\
\text { Solow Steady States (SSS): }\} \Leftrightarrow \theta \delta\left(\tilde{k}^{s}-\tilde{k}_{Y}^{s}\right) \xi^{\gamma}+\rho \\
=r\left(\tilde{k}_{Y}^{s}\right)-n\left\{\begin{array}{l}
= \\
>
\end{array}\right\} \frac{(1-\alpha) \delta \Gamma(\gamma)}{\alpha} \tilde{k}_{Y}^{s} .
\end{array}
$$

In RSS, the condition given by (11) holds with equality, which yields the steady state value of $\tilde{k}_{Y}$ and $\tilde{k}$ in RSS that are, respectively, denoted as $\tilde{k}_{Y}^{*}$ and $\tilde{k}^{*}$, where index $*$ presents a steady state value in RSS. $\tilde{k}_{Y}^{*}$ and $\tilde{k}^{*}$ cannot be analytically solved but the relationship between these two can be derived as follows:

$$
\tilde{k}_{Y}^{*}=\frac{\delta \theta \xi^{\gamma} \tilde{k}^{*}+\rho}{\delta\left(\theta \xi^{\gamma}+\frac{(1-\alpha) \Gamma(\gamma)}{\alpha}\right)}\left(\equiv \tilde{k}_{Y}^{*}\left(\tilde{k}^{*}\right)\right) .
$$


Thus, we obtain the relationship between steady state R\&D-difficultyadjusted capital stock of both the aggregate value and that devoted to final goods, $\tilde{k}$ and $\tilde{k}_{Y}$, respectively, and the growth rate of the economy in RSS as follows: ${ }^{4}$

$$
g^{*}=\frac{\frac{(1-\alpha) \delta \Gamma(\gamma)}{\alpha} \tilde{k}^{*}-\rho}{\theta+\frac{(1-\alpha)(1-\gamma)}{\alpha}} .
$$

The variable $A$ denotes the variety of intermediate goods; after these varieties are introduced, they never become trite. Consequently, the increment in $A$ is irreversible and $g^{*}\left(=g_{A}^{*}\right)$ cannot be negative. Thus, Eq. (13) immediately gives the condition of positive growth as

$$
\tilde{k}^{*}>\frac{\alpha \rho}{(1-\alpha) \delta \Gamma(\gamma)}(\equiv \underline{\tilde{k}})
$$

Accordingly, the efficiency-unit capital stock in the steady state $\tilde{k}^{*}$ must be larger than the threshold $\underline{\underline{k}}$ to satisfy the feasible condition for RSS. As is shown later, this threshold of the R\&D-efficiency-unit capital stock $\underline{\tilde{k}}$ is also derived in the necessary condition for SSS. Therefore, this threshold comprises the necessary condition on the determination of steady state (namely, it determines whether the long-run growth regime is SSS or RSS). As is shown later, this condition also determines whether the Solow or Romer transitional regime is realized. As such, this value plays a central role in regime determination in this model, and we describe the properties of this value here. The threshold value increases with $\rho$ and decreases with $\delta$, with the efficiency parameter of human capital allocated to final goods production $\beta$ being indifferent to it. Since $\frac{\alpha}{1-\alpha}$ is increasing with $\alpha$, a higher $\alpha$, which results in lower labor share and higher capital share, reduces the likelihood of RSS being realized. Furthermore, because $\Gamma(\gamma)$ is symmetric U-shaped with the lowest value at $\gamma=0.5$, a more deviating efficiency of either capital ( $\gamma$ being nearer to 0 or 1 ) provides a smaller threshold value, which increases the likelihood of RSS being realized.

We consider the mechanism for determining the steady-state capital stock $\tilde{k}^{*}$. Substituting $r=r\left(\tilde{k}_{Y}\right), \tilde{k}_{Y}^{*}=\tilde{k}_{Y}^{*}\left(\tilde{k}^{*}\right)$, and the definition of $\underline{\tilde{k}}$ into the first

\footnotetext{
${ }^{4}$ It is noteworthy that this growth rate closely resembles that of Eq. (13) in Romer (1990). One difference between the two is as follows. We have set the R\&D input as capital, which is endogenously accumulated. Therefore, (as derived below) we can endogenously derive the total endowment of capital, which is the input factor for $\mathrm{R} \& \mathrm{D}$ and for intermediate goods.
} 
and second terms in (11), we obtain the following condition that provides the R\&D-difficulty-adjusted per capita capital stock in the steady state:

$$
\underbrace{n+\rho+\frac{\theta \xi^{\gamma} \rho(\tilde{k}-\underline{\tilde{k}})}{\left(\delta \theta \xi^{\gamma} \underline{\tilde{k}}+\rho\right)}}_{\equiv L(\tilde{k} ; \alpha, \gamma, \delta, \rho, n, \theta)}=\underbrace{\alpha^{2} \eta^{-\alpha}\left(\frac{\delta \theta \xi^{\gamma} \tilde{k}+\rho}{\delta \theta \xi^{\gamma} \underline{\tilde{k}}+\rho}\right)^{\alpha-1}}_{\equiv R(\tilde{k} ; \alpha, \gamma, \delta, \eta, \rho, \theta)})^{\alpha-1} .
$$

By regarding $\tilde{k}$ as an argument of the two functions $L(\cdot)$ and $R(\cdot)$ defined in condition (15), we can easily draw these two equations as a thin solid line and a thick solid curve, respectively, as shown in Figure 1. The R\&D-difficultyadjusted capital stock in a steady growth path $\tilde{k}^{*}$ is uniquely determined by the intersection of the two equations.

From Eq.(15) or Fig. 1, it is found that a larger population growth $n$ yields a larger R\&D-difficulty-adjusted knowledge stock in RSS (namely, $\left.d \tilde{k}^{*} / d n>0\right)$. Further, this result and Eq.(14) together yield that a larger population growth $n$ results in a larger growth rate in RSS (namely, $d g^{*} / d n>$ 0 ). Specifically, population growth is negatively related to economic growth. This conclusion is the opposite of the findings of semi-endogenous growth models with labor R\&D inputs. However, this is a desirable property of the model in this study, because some empirical studies, such as Kelley (1988), Kelley and Schmidt (1995), and Ahituv (2001), report a negative correlation between population growth and economic growth. A rough sketch of this mechanism is given as follows. Condition (11) is the no-arbitrage condition between the production of goods (the profit rate is given by the middle term) and $\mathrm{R} \& \mathrm{D}$ (given by the last term). Owing to the high population rate, a lower $k_{Y}$ is necessary for equating the middle and last terms in Eq. (11). Combining this and Eq. (13), we get that a lower $\tilde{k}_{Y}$ leads to a lower growth rate.

From Figure 1, the condition for $\tilde{k}^{*}$ to be a feasible solution-namely, (14)-holding is equivalent to $L(\tilde{k})<R(\tilde{k})$ holding at $\tilde{k}=\underline{\tilde{k}}$, which yields the condition required in RSS: $\delta>\Psi(\alpha, \gamma, \eta, \rho, n)$ where $\Psi \equiv \alpha^{-\frac{1+\alpha}{1-\alpha}} \eta^{\frac{\alpha}{1-\alpha}}(n+$ $\rho)^{\frac{1}{1-\alpha}} \frac{\rho}{(1-\alpha) \Gamma(\gamma)}$.

Next, we now characterize SSS. In SSS, Eq. (11) holds with inequality, and all capital is devoted to the production of final goods; therefore, $\tilde{k}_{A}^{* *}=0$. That is, $\tilde{k}^{* *}=\tilde{k}_{Y}^{* *}$, where $* *$ denotes the steady state value in SSS. Therefore, 
substituting $\tilde{k}^{* *}=\tilde{k}_{Y}^{* *}$ into (11) yields the equilibrium capital stock in SSS:

$$
\tilde{k}^{* *}=\tilde{k}_{Y}^{* *}=\left[\frac{\alpha^{2} \eta^{-\alpha}}{\rho+n}\right]^{\frac{1}{1-\alpha}} .
$$

The inequality constituted by the second and third terms of Eq. (11) gives $\tilde{k}_{Y} \leq \underline{\tilde{k}}$. Uniting this and the inequality in Eq. (16), we have the parameter condition for SSS as $L(\underline{\tilde{k}})>R(\underline{\tilde{k}})$. Since this condition is mutually exclusive to that of RSS, the condition can also be written as follows: $\delta<\Psi(\alpha, \gamma, \eta, \rho, n)$.

Note that the conditions for RSS and SSS obtained above are mutually exclusive. Accordingly, the steady state is uniquely determined by the economy's parameter set, and an economy with $\delta>\Psi$ has RSS, and that with $\delta<\Psi$ does SSS. Thus, we summarize these results as follows.

Proposition 1. An economy has a unique long-run steady state-either positive or no growth - that is determined by the following parameter condition:

$$
\delta\left\{\begin{array}{c}
> \\
<
\end{array}\right\} \Psi(\alpha, \gamma, \eta, \rho, n) \Leftrightarrow\left\{\begin{array}{c}
\mathrm{RSS} \\
\mathrm{SSS}
\end{array}\right.
$$

That is, the parameter set $\{\alpha, \gamma, \eta, n, \rho, \delta\}$ uniquely determines either of the steady states.

Intuitively, these results imply that a country with higher R\&D efficiency and more patience realizes RSS, that is, long-run R\&D-based growth, and that a country with lower R\&D efficiency and less patience realizes SSS, that is, no-growth steady state. In contrast to the Romer model, initial endowment does not affect the long-run growth phase.

\section{Transition Dynamics and Steady States}

In this section, we analyze the transition dynamics. On the transition path, we have two regimes, characterized as $K_{A}>0$ or $K_{A}=0$. We call these the Romer regime and the Solow regime, respectively. We denote the initial R\&D-difficulty-adjusted physical capital as $\tilde{k}(0)=\tilde{k}_{0}$. Furthermore, we assume - for simplicity of discussion-zero initial endowment of human 
capital $(\tilde{h}(0)=0) .^{5}$

\subsection{Local Transition Dynamics}

A (decentralized) economic system comprises Eqs. (2), (4), (6), and (9). This system is reconstructed as a system constituted by $\tilde{k}, \tilde{c}$, and $\tilde{k}_{Y}$.

Substituting $g_{\tilde{c}}+g_{\Omega}=g_{c}+n\left(=g_{C}\right)$ and $r=\alpha^{2} \eta^{-\alpha} \tilde{k}_{Y}^{\alpha-1}$ in Eq. (9), we obtain the dynamics of $\tilde{c}$ as follows:

$$
\dot{\tilde{c}}(t)=\frac{1}{\sigma}\left\{\alpha^{2} \eta^{-\alpha} \tilde{k}_{Y}(t)^{\alpha-1}-\rho-n-\sigma \delta\left(\tilde{k}(t)-\tilde{k}_{Y}(t)\right) \xi^{\gamma}\right\} \tilde{c}(t) .
$$

This dynamic equation is common to the two regimes. Regarding the dynamics of $\tilde{k}$ and $\tilde{k}_{Y}$, each regime follows different dynamics as described below.

\subsubsection{Dynamics of the Economy in the Romer Regime}

First, we examine the Romer regime. Here, we derive the dynamics of $\tilde{k}$ in the Romer regime. From $\dot{K}(t)+\dot{H}(t)=Y(t)-C(t), K(t)=K_{Y}(t)+K_{A}(t)$, $H(t)=\frac{\gamma}{1-\gamma} K_{A}(t)$, the definition of $\tilde{k}_{Y}$, and the assumption on $\Omega(t)$, we have

$$
\begin{aligned}
& \dot{\tilde{k}}(t)=(1-\gamma)\left\{\tilde{y}\left(\tilde{k}_{Y}(t)\right)-\tilde{c}(t)\right\}-\left\{n+\delta\left(\tilde{k}(t)-\tilde{k}_{Y}(t)\right) \xi^{\gamma}\right\} \tilde{k}(t) \\
& +\gamma\left\{\frac{\dot{\tilde{k}}_{Y}(t)}{\tilde{k}_{Y}(t)}+\left(n+\delta\left(\tilde{k}(t)-\tilde{k}_{Y}(t)\right) \xi^{\gamma}\right)\right\} \tilde{k}_{Y}(t) .
\end{aligned}
$$

By using $\tilde{v}(t)=\frac{r\left(\tilde{k}_{Y}(t)\right)}{\delta \Gamma(\gamma)}$ and $g_{\tilde{v}}=r(t)-n-\frac{\delta \Gamma(\gamma) \tilde{\pi}(t)}{r(t)}$, we obtain the dynamics of $\tilde{k}_{Y}$ as

$$
\dot{\tilde{k}}_{Y}(t)=\frac{\delta \Gamma(\gamma)}{\alpha} \tilde{k}_{Y}(t)^{2}+\frac{n}{1-\alpha} \tilde{k}_{Y}(t)-\frac{\alpha^{2} \eta^{-\alpha}}{1-\alpha} \tilde{k}_{Y}(t)^{\alpha} .
$$

Thus, Eqs. (17), (18), and (19) comprise the system in the Romer regime.

Because the dynamics of $\tilde{k}_{Y}$ guided by Eq. (19) are the function that contains only $\tilde{k}_{A}$ as a variable, the dynamic properties of $\tilde{k}_{Y}$ are directly obtained from Eq. (19). The dynamics of $\tilde{k}_{Y}$ around the steady state value denoted by $\tilde{k}_{Y}^{*}$ are found to be unstable; the phase diagram of $\tilde{k}_{Y}$ is given

\footnotetext{
${ }^{5}$ See Appendix 1, which demonstrates that the case of $\tilde{h}(0)>0$ has asymptotically same properties.
} 
in Figure 2. Therefore, in order to realize RSS, it is necessary that $\tilde{k}_{Y}(t)=$ $\tilde{k}_{Y}^{*}$ must be satisfied in, at least, the neighborhood of the steady state. If $\tilde{k}_{Y}(t)<\tilde{k}_{Y}^{*}, \tilde{k}_{Y}(t)$ decreases following the dynamics of Eq. (19).

Thus, the dynamic system in the Romer regime must exist on the plane $\tilde{k}_{Y}(t)=\tilde{k}_{Y}^{*}$, which we term the Romer plane. Consequently, the system is reduced to a two-dimensional system comprising $\tilde{k}$ and $\tilde{c}$. Because the system exhibits properties similar to the dynamic properties of the Ramsey model, it can be easily verified that it has saddle stability.

\subsubsection{Dynamics of the Economy in the Solow Regime}

We now investigate the Solow regime where $\tilde{k}_{A}=0$ (which directly leads to $\left.\tilde{k}(t)=\tilde{k}_{Y}(t)\right)$ and where there is no demand for human capital. Thus, the Solow regime also exists on the two-dimensional $\{\tilde{c}-\tilde{k}\}$ plane, which we call the Solow plane. Under this condition, by using $\dot{K}(t)=Y(t)-C(t)$, $K(t)=K_{Y}(t)$, and $K_{A}=H=0$, the dynamics of $\tilde{k}$ can be given as

$$
\dot{\tilde{k}}(t)=\alpha^{2} \eta^{-\alpha} \tilde{k}(t)^{\alpha}-\tilde{c}(t)-n \tilde{k}(t) .
$$

Under $g_{A}=0,(17)$ can be written as

$$
\dot{\tilde{c}}(t)=\frac{1}{\sigma}\left\{\alpha^{2} \eta^{-\alpha} \tilde{k}_{Y}(t)^{\alpha-1}-\rho-n\right\} \tilde{c}(t),
$$

Thus, the dynamic system in this case is similar to that in the normal Ramsey model. One difference is the interest rate, which reflects the monopoly pricing in the intermediate goods sector, in which capital is one input and human capital investment is the other. A Romer-type R\&D-based growth model contains distortional intermediate goods pricing, and our model assumes that intermediate goods are produced using capital. Therefore, the interest rate (the capital rental price) is $\alpha$ times smaller than that in the normal Solow model. Other than the above, this system has the same properties as the Solow model: it has a saddle stable steady state.

\subsection{Global Transitional Dynamics and Steady States}

Combining the local transition dynamics discussed in the previous subsection and the steady state condition discussed in the previous section, we derive the global dynamics in the present study. Because we have two types of 
steady states, RSS and SSS, we obtain two types of growth patterns related to them. The phase diagrams related to these growth patterns are depicted as Figures 3 and 4, respectively.

From Proposition 1, if an economy has RSS (that is, this economy satisfies $\delta>\Psi$ ), then RSS is the economy's unique steady state. In this case, if the economy has sufficiently large R\&D-difficulty-adjusted capital stock$\tilde{k}(t) \geq \tilde{k}_{Y}^{*}$ - the economy is on the Romer regime, and converges to RSS as guided by the saddle stable path on the Romer plane $\left(\tilde{k}_{Y}=\tilde{k}_{Y}^{*}\right)$, which is drawn by the dotted region in Figure 3 (the transition path is drawn by a bold line). If an economy has a sufficiently high $R \& D$ efficiency parameter, but very small initial knowledge-adjusted capital stock- $\tilde{k}(t)<\tilde{k}_{Y}^{*}$-then the economy cannot start its growth process on the Romer regime because the path that directly converges to RSS cannot be traced while satisfying the no-arbitrage condition. Therefore, the economy rides on the Solow regime and grows by only capital accumulation until the economy has capital stock $\tilde{k}_{Y}^{*}$. The rational expected transition path on the Solow plane in this case is the path that connects to the saddle stable path on the Romer regime. Saddle stability of the Solow regime implies that this is the unique path that is consist with long-run feasibility, and this path always exist in this case. $^{6}$ Thus, the assumption of initial capital stock derives the whole economic path with RSS, as is shown below. If an economy has efficient R\&D $(\delta>\Psi)$ and a sufficiently small initial capital stock $\left(\tilde{k}(0)<\tilde{k}_{Y}^{*}\right)$, it grows without $\mathrm{R} \& \mathrm{D}$ until it reaches $\tilde{k}=\underline{\tilde{k}}$, and then, starts $\mathrm{R} \& \mathrm{D}$ activities, growing with TFP. Therefore, it experiences a switch from the Solow regime to the Romer regime, which is the regime switch described in the present study. If the economy has efficient $\mathrm{R} \& \mathrm{D}(\delta>\Psi)$ and a sufficiently large initial capital stock $\left(\tilde{k}(0)>\tilde{k}_{Y}^{*}\right)$, it grows with $\mathrm{R} \& \mathrm{D}$ in the first stage of economic development.

On the other hand, if an economy has lower R\&D efficiency, and therefore, is SSS (i.e., it satisfies $\delta<\Psi$ ), Proposition 1 implies that SSS is the economy's unique steady state. In this case, the economy fails to initiate R\&D even if it contains more initial capital or knowledge stock than the threshold value $\left(\tilde{k}(t)>\tilde{k}_{Y}^{*}\right)$. This mechanism is explained as follows. Because the parameter condition $\delta<\Psi$ implies that the unique steady state of this economy is SSS,

\footnotetext{
${ }^{6}$ It should be noted that the $\dot{\tilde{k}}=0$ lines of both the Romer and Solow regimes intersect at $\tilde{k}=\tilde{k}_{Y}=\tilde{k}_{Y}^{*}$.
} 
the equation in the condition (11) - derived from the arbitrage condition between capital and the R\&D firm - cannot hold after a finite period of time in the future. This expectation leads rational agents to refrain from investing in R\&D. Thus, this economy grows without R\&D and falls into SSS. This is the mechanism underlying the no-growth trap in this study. Some moderately developed economies fail to transit into long-run growth in the polarization process; the mechanism presented here may explain the underlying cause. The phase diagram of such an economy is depicted in Figure 4. In this case, for any initial capital endowment $\left(\tilde{k}_{0} \in(0, \infty)\right)$, the economy converges to SSS on the Solow plane. It should be noted that the intermediate goods are also monopolized in this case, and that this system is a Ramsey model with imperfect competition. The distortion is summarized in the higher interest rate: consumption growth rate is higher through the Keynes-Ramsey rule, and therefore the speed of convergence is high, but equilibrium capital stock is lower through the decreasing return properties of capital.

Proposition 2. An economy has a unique steady state and a perfect-foresight saddle-stable transition path that is convergent to the steady state. The longrun growth phase, showing either steady growth or poverty traps, is determined uniquely according to technological parameters $(\alpha, \eta$, and $\delta$ ) and preference parameter $(\rho)$. The economy with RSS (and low initial capital endowment) experiences a regime switch from capital-accumulation-based growth to REDD-based growth and realizes long-run growth. The economy with SSS lacks the profitability for RED investment and persistently stays in the Solow regime, and is thus caught in poverty traps.

\section{Optimal Growth and Economic Policy}

The previous section shows the results of the present model with regard to decentralized economic growth. Following the perfect foresight path determined by the given parameters, an economy converges to a steady state with either long-run growth or no growth. However, the present model contains a distortion in intermediate goods pricing and an unfavorable equilibrium termed as SSS. This section examines the possible roles that a government plays in developing policies to promote economic welfare and development. 


\subsection{Command Economy}

To obtain the welfare properties of a decentralized solution, consider the social planner formulation of the growth model treated above. A benevolent government is assumed to maximize the representative household's utility function (8).

From the optimal conditions, ${ }^{7}$ we have the optimal capital allocation in steady state $\tilde{k}_{Y}^{* o p}$ and the optimal growth rate of economy $g^{* o p}$, respectively, as

$$
\begin{aligned}
\tilde{k}_{Y}^{o p} & =\frac{\delta \theta \xi^{\gamma} \tilde{k}^{o p}+\rho}{\delta\left(\theta \xi^{\gamma}+\frac{(1-\alpha) \Gamma(\gamma)}{\alpha}\right)}\left(\equiv \tilde{k}_{Y}^{o p}\left(\tilde{k}^{o p}\right)\right), \\
g^{*} & =\frac{\frac{(1-\alpha) \delta \Gamma(\gamma)}{\alpha} \tilde{k}^{o p}-\rho}{\theta+\frac{(1-\alpha)(1-\gamma)}{\alpha}}
\end{aligned}
$$

Eqs. (21) and (22) imply that in steady states, the determining relationship between the economic growth rate and $\mathrm{R} \& \mathrm{D}$-difficulty-adjusted capital in a command economy accords with that in a decentralized economy.

From Eqs. (21) and (22), the condition of feasible positive growth $g^{*}\left(\tilde{k}^{o p}\right)>$ 0 is given as $\tilde{k}^{\text {opSS }}>\underline{\tilde{k}}$. It should be noted that this condition is the same as that in a decentralized economy. Thus, we obtain the following result. In a command economy, the R\&D-difficulty-adjusted capital stock, $\tilde{k}^{o p *}$, in the steady state must be larger than the threshold $\underline{\tilde{k}}$ to satisfy the feasible condition for RSS. This property is the same as that in a market economy.

This property implies that sufficient capital is necessary for steady growth. Lacking this condition, no R\&D investment (i.e., $K_{A}=g_{A}=0$ ) is optimal. For the no-growth case, R\&D-difficulty-adjusted capital stock in a command economy $\tilde{k}^{* * o p}$ is given as follows. The poverty-trap R\&D-difficulty-adjusted per capita capital stock in a command economy $\tilde{k}^{* * o p}$ is given as

$$
\tilde{k}^{* * o p}=\left[\frac{\alpha \eta^{-\alpha}}{n+\rho}\right]^{\frac{1}{1-\alpha}}\left(=\alpha^{-\frac{1}{1-\alpha}} \tilde{k}_{Y}^{* *}>\tilde{k}_{Y}^{* *}\right) .
$$

Further, we derive the R\&D-difficulty-adjusted per capita capital stock for the steady state under the case with positive $\mathrm{R} \& \mathrm{D} \tilde{k}^{o p *}$. The counterpart of Eq. (15) - that is, the equation providing the steady-growth R\&D-difficultyadjusted per capita capital stock in a command economy $\tilde{k}^{* o p}$-is obtained

\footnotetext{
${ }^{7}$ See Appendix A2 for detailed derivations.
} 
as follows:

$$
\underbrace{n+\rho+\frac{\theta \xi^{\gamma} \rho(\tilde{k}-\underline{\tilde{k}})}{\left(\delta \theta \xi^{\gamma} \underline{\tilde{k}}+\rho\right)}}_{\equiv L(\tilde{k} ; \alpha, \gamma, \delta, \rho, n, \theta)}=\underbrace{\alpha \eta^{-\alpha}\left(\frac{\delta \theta \xi^{\gamma} \tilde{k}+\rho}{\delta \theta \xi^{\gamma} \underline{\tilde{k}}+\rho^{2}}\right)^{\alpha-1}}_{\equiv R^{o p}(\tilde{k} ; \alpha, \gamma, \delta, \eta, \rho, \theta)} .
$$

$L(\tilde{k} ; \alpha, \gamma, \delta, \rho, n, \theta)$ is identical to the case of a market economy, and $R^{o p}(\tilde{k} ; \alpha, \gamma, \eta, \rho, \theta)$ is $\alpha$ times the $\mathrm{R}$ in Eq. (15), $R(\tilde{k} ; \alpha, \gamma, \delta, \eta, \rho, \theta)$. $R^{o p}$ is drawn in Figure 1 as a broken line. Because the difference between a decentralized economy and a command economy is that $R$ is $\alpha$ times $R^{o p}$, the properties of the steady state are similar in both cases. In the steady state of an optimal economy, lower $\rho, \eta$, and $n$ lead to a higher per capita GDP growth rate. This is the same as in the steady state in a decentralized economy. However, equilibrium capital stock in a command economy is larger than that in a decentralized economy. Therefore, the growth rate of this economy is higher than that in a decentralized economy.

Because $L(\tilde{k})$ and $R^{o p}(\tilde{k})$ are monotonous increasing and decreasing functions, respectively, the condition $\tilde{k}^{o p S S}>\underline{\tilde{k}}$ is equivalent to

$$
L(\underline{\tilde{k}})<R^{o p}(\underline{\tilde{k}}) .
$$

Substituting $\underline{\tilde{k}}$ into $L(\tilde{k})$ and $R(\tilde{k})$, we obtain the following inequality:

$$
\delta>\Psi^{o p}(n, \eta, \rho, \alpha)
$$

where $\Psi^{o p} \equiv \alpha^{\frac{1}{1-\alpha}} \Psi$.

Summarizing the above discussions, we obtain the equilibrium capital stock in a command economy $\tilde{k}^{o p}$ as follows:

Proposition 1'. An economy has a unique optimal long-run steady state of positive growth or no-growth traps that is determined by the following condition:

$$
\begin{aligned}
& \tilde{k}^{o p}=\left\{\begin{array}{lll}
\tilde{k}^{* o p} & \text { if } & \delta>\Psi^{o p} \\
\tilde{k}^{* * o p} & \text { if } & \delta<\Psi^{o p}
\end{array}\right\} \\
& \Rightarrow \text { Long-run optimal growth is }\left\{\begin{array}{l}
\text { positive growth (RSS) } \\
\text { no growth (SSS) }
\end{array}\right.
\end{aligned}
$$

Because $0<\alpha^{\frac{1}{1-\alpha}}<1$ for $0<\alpha<1$, it should be noted that $\Psi^{o p}<\Psi$, which implies that the necessary condition for RSS is less restrictive in a command economy than in a decentralized economy. 


\subsection{Effects of Economic Policies}

In this section, we introduce subsidies and taxes into our model and discuss the effectiveness of economic policies. We propose that a constant rate subsidy $s>0$ (or a tax if $s<0$ ) is levied (or provided) for interest (rental price of capital) and the profit of the intermediate sector, as below:

$$
\begin{aligned}
& r^{s} \equiv\left(1+s_{r}\right) r=\left(1+s_{r}\right) \alpha^{2} \frac{Y}{K_{Y}}, \\
& \pi^{s} \equiv\left(1+s_{\pi}\right) \pi=\left(1+s_{\pi}\right) \alpha(1-\alpha) \frac{Y}{A},
\end{aligned}
$$

where $s_{r}$ and $s_{\pi}$ represent the rate of interest and profit subsidies, respectively.

The existence of distortion in the intermediate goods market leads the decentralized economy to accumulate less R\&D-difficulty-adjusted capital stock than a command economy. For this reason, policies that promote capital accumulation by subsidizing the interest rate always improve economic welfare.

The government is assumed to finance these subsidies using lump-sum tax revenues; total tax revenue is expressed as $T^{L S}$. We assume that the government maintains a balanced fiscal policy: the budget constraint $s_{r} K+$ $s_{\pi} A=T^{L S}$ is always satisfied. Translating $r$ and $\pi$ in Eqs. (17) and (19) to $r^{s}$ and $\pi^{s}$, we determine both dynamics after taxation (or subsidy) as follows:

$$
\begin{aligned}
\dot{\tilde{c}} & =\frac{1}{\sigma}\left\{\left(1+s_{r}\right) \alpha^{2} \eta^{-\alpha} \tilde{k}_{Y}^{\alpha-1}-\rho-n-\sigma \delta\left(\tilde{k}-\tilde{k}_{Y}\right)\right\} \tilde{c} \\
\dot{\tilde{k}}_{Y} & =\frac{\delta}{\alpha}\left(1+s_{\pi}\right) \tilde{k}_{Y}^{2}+\frac{n}{1-\alpha} \tilde{k}_{Y}-\left(1+s_{r}\right) \frac{\alpha^{2} \eta^{-\alpha}}{1-\alpha} \tilde{k}_{Y}^{\alpha} .
\end{aligned}
$$

For optimal growth, Eqs. (28) and (29) must correspond with Eqs. (39) and (40) (in Appendix), respectively.

Thus, we obtain the result that optimal growth and capital allocation are realized by the following subsidy policy:

$$
s_{r}^{*}=\frac{1}{\alpha}-1>0, \quad s_{\pi}^{*}=0 .
$$

Because $\alpha \in(0,1), s_{r}^{*}$ is always constant and negative, implying that this policy is perennially effective and that it increases economic welfare.

The above part showed that a governmental policy of interest rate subsidies can increase the economy's welfare. However, can an optimal subsidy 
deliver an economy from a poverty trap onto steady growth? The answer, at least partially, is affirmative.

To answer this question, we provide Table 1 that summarizes the results of the determination of steady states on market and command economies, derived in Propositions I and I'. For both market and command economies, the steady states are determined by R\&D efficiency $\delta$ and other deep parameters $n, \eta, \rho$, and $\alpha$ that are contained in $\Psi$ and $\Psi^{o p}$. This table implies that the necessity of R\&D efficiency for RSS is less restrictive in a command economy than in a market economy, and as such, if a country has the parameter set $\Psi^{o p}<\delta<\Psi$ and a market economy without a subsidy, the country is stuck in SSS although the optimal steady state of the economy is long-run positive growth (RSS). In this case, the country is capable of long-run positive growth, but monopoly power exercised in the decentralized economy draws the economy into a no-growth trap. In this situation, the optimal subsidy policy transforms the economy's steady state from SSS to RSS. In this manner, the economy with $\Psi^{o p}<\delta<\Psi$ can shift from a poverty trap to long-run growth through relevant subsidy policies. Thus, the necessity of R\&D efficiency for RSS is less restrictive in a command economy than in a market economy. As a result, an economy with middle-range R\&D efficiency fails to realize market-economy-driven R\&D-based long-run growth, but relevant subsidizing policies can enable it to experience long-run growth.

If an economy's parameter set is $\delta<\Psi^{o p}$, its situation is worse. In this case, the economy has SSS as the optimal steady state for any stock variable endowments; therefore, convergence to a no-growth equilibrium (SSS) is the economy's welfare maximizing path, and consequently, even if the government provides relevant subsidies derived above, SSS stays. If this country desires long-run growth, relevant parameters (for example, R\&D efficiency $\delta$ ) must be improved. Further, any ODA, such as licensing technology (which implies an increment in knowledge $A$ in our model), capital contribution (which implies an increment in capital stock $K$ ), and setting up of an educational institute (which tries human capital accumulation $H$ ), makes no change in the determination factor of the steady state because the condition given in Proposition I' contains only deep parameters and does not endow human or physical capital stock or knowledge accumulation. Thus, the steady states of the aided countries remain completely unaffected (if such accumulation has no external positive effects on the efficiency condition of R\&D through deep parameters). The only result of such ODA is a jump in the 
same transition path. Consequently, the economy will fall into a no-growth path in the long run by adjusting the stock of $A$ or $K$. Therefore, for effective ODA, it is necessary to aid an economy to make structural changes that improve deep parameters, for example, enhancing efficiency parameters such as the cost of the production of intermediate goods $\eta$ or R\&D efficiency $\delta$.

Thus, the above results can be summarized as follows.

Proposition 3. Social welfare increased with the interest-rate subsidy rate $s_{r}^{*}$ which increases the long-run growth rate along a steady growth path. Moreover, the subsidy $s_{r}^{*}$ extricates an economy from poverty traps if its RSS path is optimal (that is, if condition $\delta>\Psi^{o p}$ is satisfied). Setting an economy with SSS on a long-run growth path requires structural improvement. Technology licensing or capital stock will not be effective for this purpose.

\section{Conclusion}

This study developed a model with endogenously-accumulated R\&D inputs and investigated the mechanics of the growth process with a regime switch. It shows that the equilibrium (physical) capital stock is positively related to the long-run growth rate. Capital stock depends negatively on the cost of intermediate goods and the subjective discount rate, which determines the steady state of the economy. Each economy has a unique steady state and a unique transition path converging to it. To achieve long-run growth, a country must have high R\&D efficiency, low cost of intermediate goods, and a subjective discount rate. An economy that does not satisfy these conditions languishes in a no-R\&D regime and a poverty trap. If the economy has low initial endowment of (R\&D-difficulty-adjusted) capital and a steady state with a long-run positive growth, a regime switch occurs. Low capital endowment lowers $R \& D$ profitability on $R \& D$, and hence, no $R \& D$ takes place. Further, when capital stock becomes sufficient for supporting R\&D, the economy will achieve long-run growth through $R \& D$.

Because our model incorporates a monopoly on the production of intermediate goods, the economy contains a distortion, and therefore, the economic policy is effective. This distortion appears in the economy's interest rate and results in lesser long-run capital stock. Therefore, governmental policies for subsidizing the interest rate and augmenting steady-state capital can 
steer the economy to an optimal path. Economic welfare can always be improved through this subsidization. However, under some parameter sets, the economy's optimal path is a no-growth path. In this case, some policies for guiding the economy toward long-run growth by increasing physical capital or knowledge capital will not enhance economic welfare. Effective aid should improve the economic environment for R\&D by, for example, enhancing the productivity of intermediate goods or the efficiency of R\&D investment. A patent is regarded as a written or a formal knowledge, whereas deep parameters such as R\&D efficiency and the productivity of intermediate goods are considered non-written or implicit knowledge. Future research should focus on economic analysis and foreign aid in order to gain a deeper sight into this topic.

\section{Appendix}

\section{A1. Positive Initial Endowment of Human Capital}

In this appendix, we consider the case of $H(0)=H_{0}>0$. If the profit rate of human capital is equated with physical capital, it is simply the Romer regime, and as such, in this section, we consider the case wherein the profit rate of human capital is smaller than that of physical capital. In this case, $\dot{H}=0$ and $r>r_{H}$ hold, and therefore, human capital endowment is fixed at the initial endowment $H_{0}$, and $\mathrm{R} \& \mathrm{D}$ is executed to hold the no-arbitrage condition on capital profit rate $r$. Then $r_{H}$ is determined at the level that satisfies the zero-profit condition on R\&D.

Therefore, the equilibrium condition on this regime is given by

$$
\frac{\partial \Pi}{\partial K_{A}}=(1-\gamma) \delta \frac{\xi_{A}^{-\gamma}}{N(t)} \bar{V}-r=0, \quad \frac{\partial \Pi}{\partial H}=\gamma \delta \frac{\xi_{A}^{1-\gamma}}{N(t)} \bar{V}-r_{H}=0,
$$

where $\xi_{A}(t) \equiv \frac{K_{A}}{H}$. From these two equations, we have

$$
\tilde{v}=\frac{\xi_{A}^{\gamma}}{(1-\gamma) \delta} r, \quad \text { and } \quad r_{H}=\frac{\gamma \xi_{A}}{1-\gamma} r
$$

Thus, for the steady state, $\xi_{A}=$ (const) is also necessary in this case. Because $H_{0}$ is constant, $K_{A}$ also is constant, and we denote it as $\bar{K}_{A}$. However, the 
growth rate under $\bar{K}_{A}$ is given as

$$
g_{A}(t)=\frac{\bar{K}_{A}}{A(t) N(t)} \xi_{A}^{\gamma} .
$$

Therefore, after the long run, the growth rate converges to $\lim _{t \rightarrow \infty} g_{A}(t)=0$; namely, the system asymptotically deceases the growth rate and converges to the Solow regime.

\section{A2. Command Economy and Optimal Conditions}

To obtain the welfare properties of the decentralized solution, we consider the social planner formulation of this growth model. A benevolent government is assumed to maximize the representative household's utility function Eq. (8). Therefore, the Hamiltonian of this government can be written as

$$
\begin{aligned}
\mathcal{H}(t)= & \frac{c(t)^{1-\sigma}-1}{1-\sigma}+\lambda(t)(\underbrace{\eta^{-\alpha} K_{Y}(t)^{\alpha} N(t)^{1-\alpha} A(t)^{1-\alpha}}_{Y}-c(t) N(t)-I_{H}(t)) \\
& +\mu(t) \delta \frac{\left(K(t)-K_{Y}(t)\right)^{1-\gamma} H(t)^{\gamma}}{N(t)}+\lambda_{H}(t) I_{H}(t),
\end{aligned}
$$

where $\lambda, \mu$, and $\lambda_{H}$ are the shadow prices of per capita capital stock, knowledge, and human capital, respectively. The optimal conditions are obtained as follows:

$$
\begin{aligned}
\lambda(t) N(t) & =c(t)^{-\sigma} \\
\lambda(t) & =\lambda_{H}(t) \\
\lambda(t) \alpha \eta^{-\alpha} K_{Y}(t)^{\alpha-1}\{ & A(t) N(t)\}^{1-\alpha}= \\
(1-\gamma) \mu(t) \delta \frac{\left(K(t)-K_{Y}(t)\right)^{-\gamma} H(t)^{\gamma}}{N(t)} & \\
\rho \lambda(t)-\dot{\lambda}(t) & =(1-\gamma) \mu(t) \delta \frac{\left(K(t)-K_{Y}(t)\right)^{-\gamma} H(t)^{\gamma}}{N(t)}, \\
\rho \lambda_{H}(t)-\dot{\lambda}_{H}(t) & =\gamma \mu(t) \delta \frac{\left(K(t)-K_{Y}(t)\right)^{1-\gamma} H(t)^{\gamma-1}}{N(t)} \\
\rho \mu(t)-\dot{\mu}(t) & =\lambda(t)(1-\alpha) \eta^{-\alpha} K_{Y}(t)^{\alpha} N(t)^{1-\alpha} A(t)^{-\alpha} .
\end{aligned}
$$


Using Eqs. (31), (34), and (36) and the notation $\tilde{k}_{Y}$, we derive the following equations:

$$
\begin{aligned}
& \rho-g_{\lambda}(t)=\alpha \eta^{-\alpha} \tilde{k}_{Y}(t)^{\alpha-1} \\
& \rho-g_{\mu}(t)=\frac{1-\alpha}{\alpha} \delta \Gamma(\gamma) \tilde{k}_{Y}(t) .
\end{aligned}
$$

(34) and (35) yield the optimal rate between physical capital $K_{Y}$ and human capital $H$ as $H=\frac{\gamma}{1-\gamma} K_{Y}$; namely, we have the rate between physical capital and human capital, $\xi$, in both the market and command economies in this study. Using $\xi$, the growth rate can also be written as $g_{A}=\delta\left(\tilde{k}-\tilde{k}_{Y}\right) \xi^{\gamma}$.

From Eqs. (31) and (37) and the definitions of $\tilde{c}$ and $\tilde{k}$, the following Euler equation is obtained:

$$
g_{\tilde{c}}(t)=\frac{1}{\sigma}\left\{\alpha \eta^{-\alpha} \tilde{k}_{Y}(t)^{\alpha-1}-\rho-n-\sigma \delta\left(\tilde{k}(t)-\tilde{k}_{Y}(t)\right) \xi^{\gamma}\right\}
$$

From Eqs. (33), (37), and (38), eliminating $\lambda$ and $\mu$ yields

$$
g_{\tilde{k}_{Y}}(t)=\frac{1}{1-\alpha}\left[\frac{\delta(1-\alpha) \Gamma(\gamma)}{\alpha} \tilde{k}_{Y}(t)+n-\alpha \eta^{-\alpha} \tilde{k}_{Y}(t)^{\alpha-1}\right] .
$$

The system consists of the following dynamic equations: (2), (39), and (40). These equations imply that $g_{\tilde{k}_{Y}}=g_{\tilde{k}}$ and $g_{A}=g_{k}=g_{c}=\delta\left(\tilde{k}-\tilde{k}_{Y}\right)$ must hold in a steady state. Substituting these conditions into Eqs. (2), (39), and (40), we obtain the following equations denoting the steady state of the command economy:

$$
\begin{aligned}
& \rho+\sigma \delta\left(\tilde{k}^{* o p}-\tilde{k}_{Y}^{* o p}\right) \xi^{\gamma}=\alpha \eta^{-\alpha} \tilde{k}_{Y}^{* o p \alpha-1}-n \\
& \eta^{-\alpha} \tilde{k}_{Y}^{* o p \alpha}-\tilde{c}^{* o p}-\left\{n+\delta\left(\tilde{k}^{* o p}-\tilde{k}_{Y}^{* o p}\right) \xi^{\gamma}\right\} \tilde{k}^{* o p}=0 \\
& \alpha \eta^{-\alpha} \tilde{k}_{Y}^{* o p \alpha-1}-n=\frac{(1-\alpha) \Gamma(\gamma)}{\alpha} \delta \tilde{k}_{Y}^{* o p}
\end{aligned}
$$

By eliminating $\alpha \eta^{-\alpha} \tilde{k}_{Y}^{* o p \alpha-1}-n$ from (41) and (43), we obtain the result that optimal capital allocation in the steady state in a command economy is the same as that in a market economy given by (12). Furthermore, the growth rate for given R\&D-difficulty-adjusted capital stock in a command economy is the same as that in a market economy given by (13). 
Acknowledgement The author thanks Kazuo Mino, Koichi Futagami, Akihisa Shibata, Katsuya Takii, Akira Momota, Yasutomo Murasawa, Yoichi Gokan, Katsunori Yamada, and Yui Nakamura for their many useful comments and suggestions. Last, the financial support from the Japan Society for the Promotion of Science (JSPS Wakate B) is gratefully acknowledged. Any remaining errors are the sole responsibility of the author.

\section{References}

[1] Abramovitz M, David PA (1973) Reinterpreting economic growth: Parables and realities. American Economic Review 63:428-439

[2] Aghion P, Howitt P (1992) A model of growth through creative destruction. Econometrica 60:323-351

[3] Aghion P, Howitt P (1998) Endogenous growth theory. MIT Press, Cambridge

[4] Ahituv A (2001) Be fruitful or multiply: On the interplay between fertility and economic development. Journal of Population Economics 14:5171

[5] Arnold LG (2000) Stability of the market equilibrium in Romer's model of endogenous technological change: A complete characterization. Journal of Macroeconomics 22:69-84

[6] Boone P (1996) Politics and the effectiveness of foreign aid. European Economic Review 40:289-329

[7] Burnside C, Dollar D (2000) Aid, policies, and growth. American Economic Review 90:847-868

[8] Chandler AD (1990) Scale and scope: The dynamics of industrial capitalism. Belknap Press, Cambridge

[9] Funke M, Strulik H (2000) On endogenous growth with physical capital, human capital and product variety. European Economic Review 44:491515 
[10] Galor O, Moav O (2004) From physical to human capital accumulation: Inequality and the process of development. Review of Economic Studies 71:1001-1026

[11] Grossman M, Helpman E (1991) Innovation and growth in the global economy. MIT Press, Cambridge

[12] Hayami Y, Ogasawara J (1999) Changes in the sources of modern economic growth: Japan compared with the United States. Journal of Japanese and International Economies 13:1-21

[13] Howitt P, Aghion P (1998) Capital accumulation and innovation as complementary factors in long-run growth. Journal of Economics Growth 3:111-130

[14] Irmen A (2005) Extensive and intensive growth in a neoclassical framework. Journal of Economic Dynamics and Control 29:1427-1448

[15] Jones CI (1995a) Time series tests of endogenous growth models. Quarterly Journal of Economics 110:495-525

[16] Jones CI (1995b) R\&D-based models of economic growth. Journal of Political Economy 103:759-784

[17] Jones CI (2002) Introduction to Economic Growth 2nd Edition. W.W. Norton \& Company, Inc.

[18] Kelley AC (1988) Economic consequence of population change in the third world. Journal of Economic Literature 26:1685-1728

[19] Kelley AC, Schmidt RM (1995) Aggregate population and economic growth correlations: The role of the components of demographic change. Demography 32:543-555

[20] Krugman P (1994) The myth of Asia's miracle. Foreign Affairs 73:62-78.

[21] Kuwahara S (2007) The mechanics of economic growth through capital accumulation and technological Progress. The Japanese Economic Review 58:504-523

[22] Matsuyama K (1999) Growing through cycles. Econometrica 67:335-347 
Table 1: Three Types of Steady States

\begin{tabular}{|c||c|c|c|}
\hline $\begin{array}{c}\text { Equilibrium Type } \\
\text { (Condition) }\end{array}$ & $\begin{array}{c}\text { A } \\
\left(\delta<\Psi^{o p}\right)\end{array}$ & $\begin{array}{c}\text { B } \\
\left(\Psi^{o p}<\delta<\Psi\right)\end{array}$ & $\begin{array}{c}\text { C } \\
(\Psi<\delta)\end{array}$ \\
\hline \hline Market Economy & SSS & SSS & RSS \\
\hline Command Economy & SSS & RSS & RSS \\
\hline
\end{tabular}

[23] Matsuyama K (2001) Growing through cycles in an infinitely lived agent economy. Journal of Economic Theory 100:220-234

[24] Quah D (1996) Empirics for economic growth and convergence. European Economic Review 40:1353-1375

[25] Quah D (1997) Empirics for growth and distribution: Polarization, stratification, and convergence clubs. Journal of Economic Growth 2:27-59

[26] Romer PM (1990) Endogenous technological change. Journal of Political Economy 98:S71-S102

[27] Segerstrom, PS (1998) Endogenous growth without scale effects. American Economic Review 99: 1290-1310

[28] Solow RM (1957) Technical change and the aggregate production function. Review of Economics and Statistics 39:312-320

[29] Young A (1995) The tyranny of numbers: Confronting the statistical realities of the East Asian growth experience. Quarterly Journal of Economics 110:641-680

[30] Zilibotti F (1995) A Rostovian model of endogenous growth and underdevelopment traps. European Economic Review 39:1569-1602 


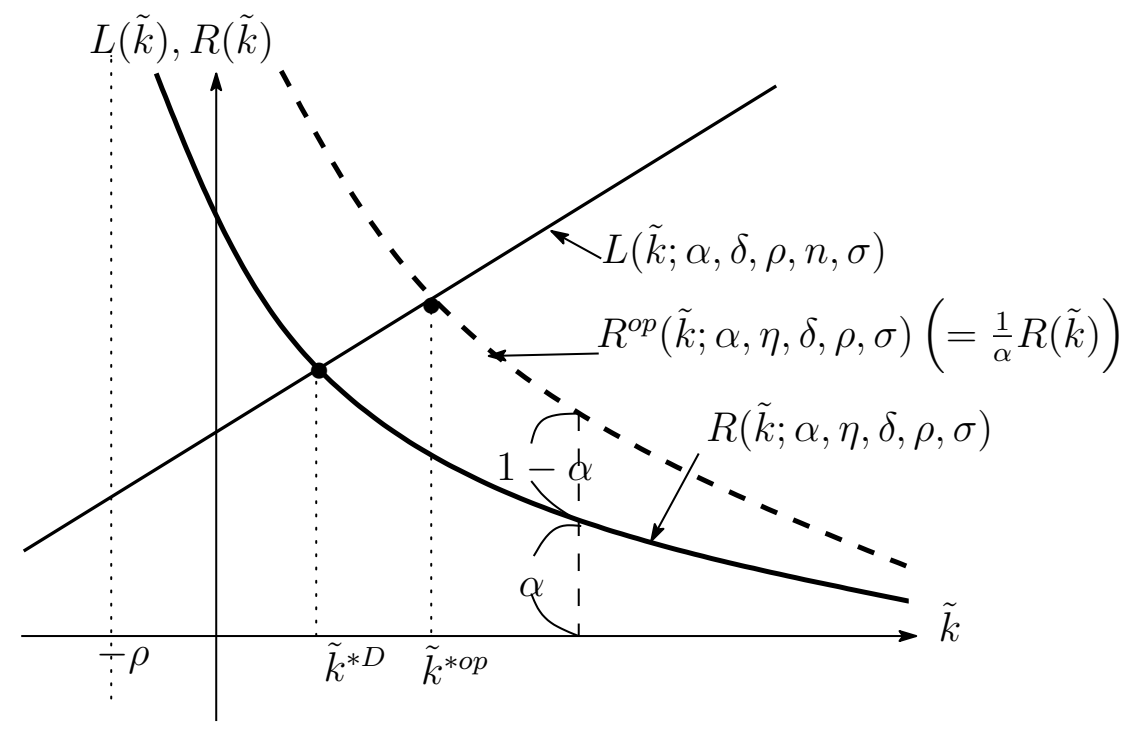

Figure 1: Equilibrium Stock of the R\&D-Difficulty-Adjusted Capital in Steady Growth

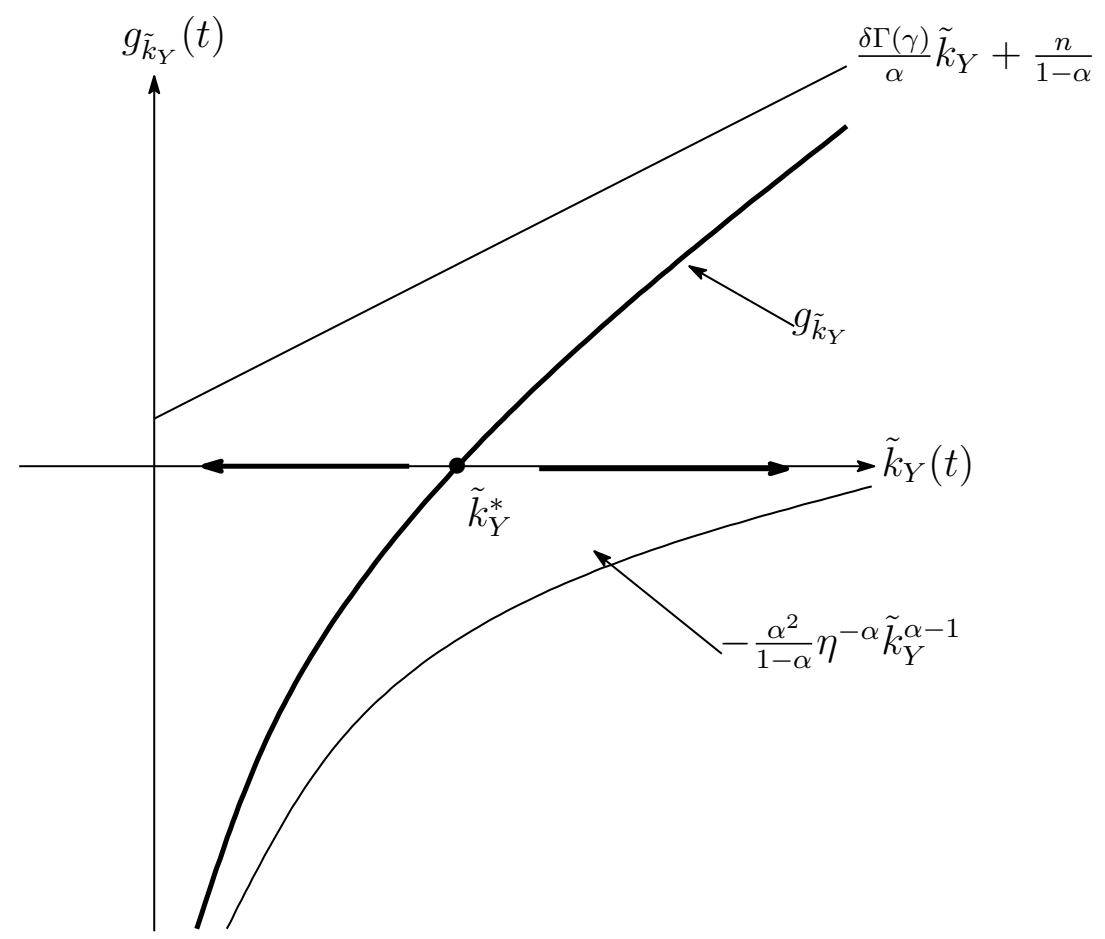

Figure 2: Dynamics of $\tilde{k}_{Y}$ 


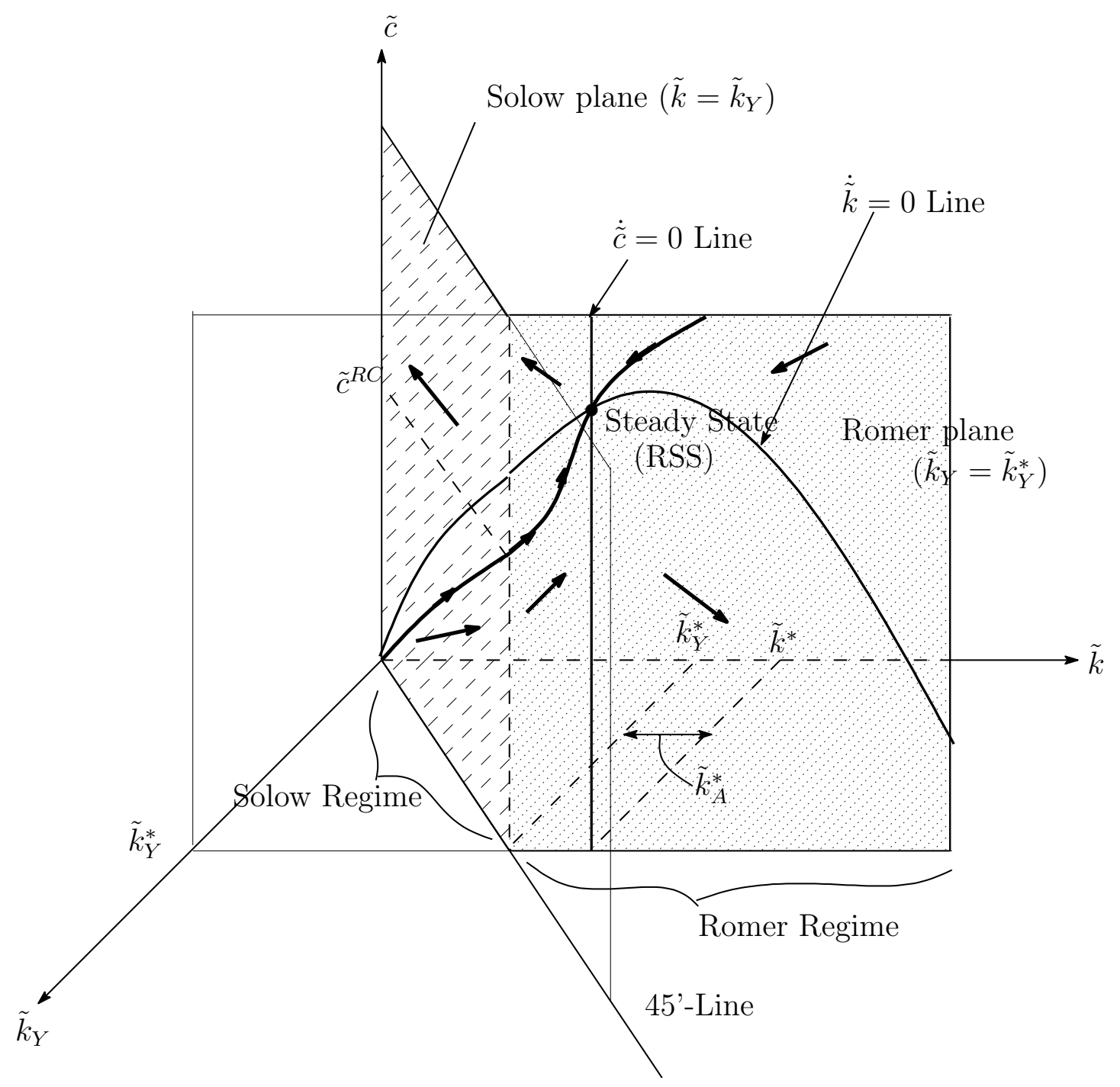

Figure 3: Global Phase Dynamics (Long-run Growth Case) 


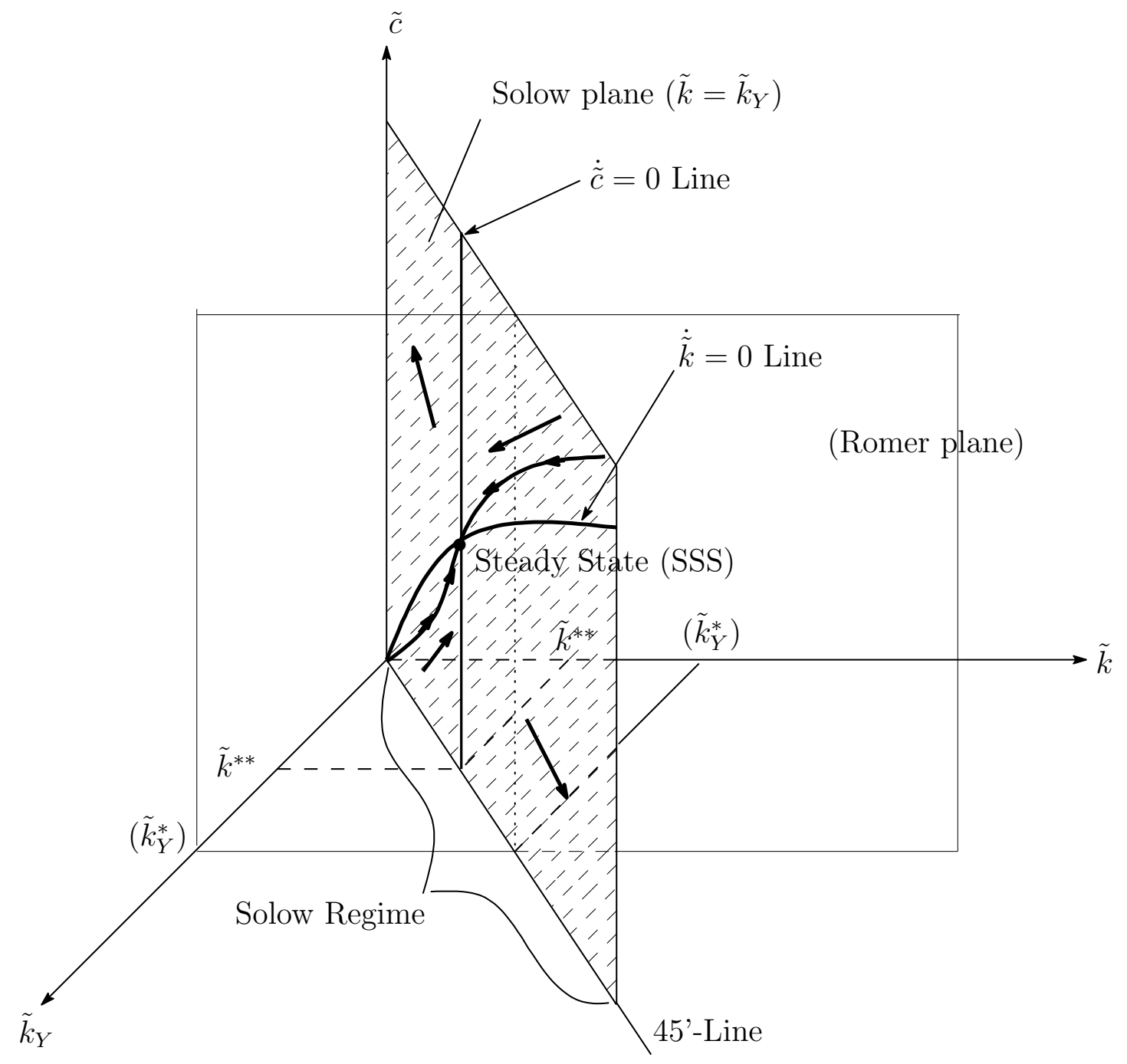

Figure 4: Global Phase Dynamics (No-growth Case) 